\title{
Costs and global impacts of black carbon abatement strategies
}

\author{
By KRISTIN RYPDAL ${ }^{1}$, NATHAN RIVE ${ }^{1}$, TERJE K. BERNTSEN ${ }^{1 *}$, ZBIGNIEW KLIMONT ${ }^{2}$, \\ TORBEN K. MIDEKSA ${ }^{1}$, GUNNAR MYHRE ${ }^{1}$ and RAGNHILD B. SKEIE ${ }^{1},{ }^{1}$ CICERO, P.O. Box \\ 1129 Blindern, N-0318 Oslo, Norway; ${ }^{2}$ International Institute for Applied Systems Analysis (IIASA), \\ A-2361 Laxenburg, Austria
}

(Manuscript received 6 August 2008; in final form 18 May 2009)

\begin{abstract}
Abatement of particulate matter has traditionally been driven by health concerns rather than its role in global warming. Here we assess future abatement strategies in terms of how much they reduce the climate impact of black carbon (BC) and organic carbon (OC) from contained combustion. We develop global scenarios which take into account regional differences in climate impact, costs of abatement and ability to pay, as well as both the direct and indirect (snow-albedo) climate impact of BC and OC. To represent the climate impact, we estimate consistent region-specific values of direct and indirect global warming potential (GWP) and global temperature potential (GTP). The indirect GWP has been estimated using a physical approach and includes the effect of change in albedo from $\mathrm{BC}$ deposited on snow. The indirect GWP is highest in the Middle East followed by Russia, Europe and North America, while the total GWP is highest in the Middle East, Africa and South Asia. We conclude that prioritizing emission reductions in Asia represents the most cost-efficient global abatement strategy for BC because Asia is (1) responsible for a large share of total emissions, (2) has lower abatement costs compared to Europe and North America and (3) has large health cobenefits from reduced $\mathrm{PM}_{10}$ emissions.
\end{abstract}

\section{Introduction}

Emissions of black carbon (BC) particles to the air have been shown to cause significant warming of the climate system (Haywood and Shine, 1995; Forster et al., 2007; Ramanathan and Carmichael, 2008). The absorption of solar radiation by $\mathrm{BC}$ particles in the atmosphere (referred to as the direct effect) gives a positive radiative forcing (RF). Following up on previous work by Warren (1984) and others, Hansen and Nazarenko (2004) and Flanner et al. (2007) demonstrate that BC also reduces the surface albedo of snow and ice, further contributing to a warming of the climate. Moreover, Hansen et al. (2005), Hansen and Nazarenko (2004) and Flanner et al. (2007) found that surface albedo change from aerosols deposited on snow and ice has a much greater climate efficacy ${ }^{1}$ than the emissions of $\mathrm{CO}_{2}$ or other mechanisms influencing the climate. Over the last few years, there have been indications that $\mathrm{BC}$ also has a significant semi-direct effect, since the absorbing aerosols can,

\footnotetext{
* Corresponding author.

e-mail: t.k.berntsen@geo.uio.no. DOI: $10.1111 / \mathrm{j} .1600-0889.2009 .00430 . x$

${ }^{1}$ The global temperature response per unit forcing relative to the response to $\mathrm{CO}_{2}$ forcing.
}

depending on altitude, either inhibit cloud formation or increase the evaporation of clouds (Hansen et al., 1997; Ackerman et al., 2000; Cook and Highwood, 2004; Koren et al., 2004).

$\mathrm{BC}$ is emitted as a result of incomplete combustion of fossil fuels, industrial processes and biomass burning (Bond et al., 2004). Organic carbon (OC) aerosols are co-emitted with BC, and $\mathrm{OC}$ emissions are particularly large from biomass burning. In contrast to $\mathrm{BC}$, emissions of OC generate a negative RF (cooling effect). For biomass burning, the warming effect of $\mathrm{BC}$ is of a similar magnitude to the cooling effect of OC (Ramaswamy et al., 2001; Forster et al., 2007). At present, the contributions to global RF of primary emission of $\mathrm{BC}$ and $\mathrm{OC}$ from fossil and biofuel are estimated at $+0.20 \pm 0.15$ and $-0.05 \pm 0.05 \mathrm{Wm}^{-2}$, respectively (Forster et al., 2007). Activities that emit BC emissions, in addition to emitting OC, also cause co-emissions of a variety of gaseous species (e.g. $\mathrm{NO}_{x}, \mathrm{CO}$ and VOCs) that affect climate through ozone formation and changes in the methane lifetime (Berntsen et al., 2005; Naik et al., 2007).

$\mathrm{BC}$ has a relatively short atmospheric lifetime (Schulz et al., 2006), resulting in regionally inhomogeneous concentrations in the air. Furthermore, the climate effect of BC in the air will be different in different regions due to differences in climate, radiation properties and deposition pathways (Forster et al., 2007). Consequently, the climate effect per unit of $\mathrm{BC}$ emitted will be 
different in different parts of the world. Unlike abating $\mathrm{CO}_{2}$, this implies that the benefits of abating one tonne $\mathrm{BC}$ will be greater in some regions than in others.

Despite its impact on climate, BC is currently outside the framework of the Kyoto Protocol under the United Nations Framework Convention on Climate Change (UNFCCC), which is limited to $\mathrm{CO}_{2}, \mathrm{CH}_{4}, \mathrm{~N}_{2} \mathrm{O}$, HFCs, PFCs and $\mathrm{SF}_{6}$. Thus, measures to abate it fall under the umbrella of abating particulate matter (PM) emissions to reduce human health problems because elevated PM concentrations have been associated with adverse health effects (WHO, 2004). While it traditionally has been classified as a local air pollution problem, in recent years more attention has been drawn to its role in long-range transboundary air pollution. The revised European Union National Emission Ceiling (NEC) Directive proposes national emission ceilings for fine PM $\left(\mathrm{PM}_{2.5}\right)$ for 2020. Furthermore, the Convention on Long Range Transboundary Air Pollution (LRTAP) will address fine PM in Europe in the forthcoming revision of the Gothenburg Protocol and from a scientific perspective in the ongoing activities assessing transport of air pollution in the northern hemisphere (HTAP, 2007).

Since BC is a subcomponent of PM from combustion (Bond et al., 2004) reduced RF from BC will be a cobenefit of strategies targeting PM emissions. The question remains, however, whether such abatement strategy can provide optimal benefits in terms of reduced RF or ensure global cost-effectiveness. To our knowledge, no existing studies attempt a global integrated assessment of BC abatement with respect to costs and benefits in a climate context, although Bond and Sun (2005) and Boucher and Reddy (2008) discussed cost-effectiveness of reducing BC versus $\mathrm{CO}_{2}$ from the largest anthropogenic emission sources. In this paper, we focus on the RF reduction as the primary benefit of $\mathrm{BC}$ abatement, and optimize emission reductions from the current legislation emission (CLE) level to achieve further BC RF reductions of 10, 20 and $30 \%$. We generate three scenarios for BC abatement in 2030 with the following main areas of emphasis: (1) RF reductions per tonne of BC abated; (2) cost-effectiveness in reducing RF and (3) ability to pay for reductions. The scenarios are explained in more detail in Section 4, with the inputs described in Section 2 (emission data and abatement costs) and Section 3 (weighting of climate effects).

In these scenarios, we account for the RF impact of both BC and $\mathrm{OC}$ to account for the net effect on the climate of any abatement we consider. Abatement options from different activities feature differing ratios of $\mathrm{BC}$ to $\mathrm{OC}$, and thus by accounting for both species we compare the effectiveness of RF reduction from each option. Furthermore, we take into account only abatement of contained combustion emissions. The goal is to isolate the abatement of $\mathrm{BC}$ and $\mathrm{OC}$ emissions from other potential climate-impacting species such as $\mathrm{SO}_{2}$ and $\mathrm{CO}$ - which may arise from the control of open burning. The climate impact of $\mathrm{CO}$ from open emissions abatement is approximately the same as that of $\mathrm{BC}$, which would skew our optimisation results. The exclusion of open burning is further justified by the fact that the biomass-burning emissions of $\mathrm{OC}$ are more important and the net climate effect of reductions in $\mathrm{BC}$ emissions will be close to zero (Ramaswamy et al., 2001; Bond et al., 2004; Forster et al., 2007).

Because of the focus on global climate effects, we chose an aggregated regional level of analysis. This aggregation level reflects differences in radiative properties of $\mathrm{BC}$ and regional differences in economic development. The regions also represent different status of implementation of air quality policies and thus different costs for further abatement from the CLE emission level. The regions considered are EU17, Rest of Europe (RoE), Russia (RUS), North America (NAM), Latin America (LAM), East Asia (EAS), Centrally Planned Asia (CPA), South Asia (SAS), Japan (JPN), the Pacific OECD (POE), Africa (AFR) and the Middle East (MIDE).

\section{Inventory data and abatement costs}

This section describes how we got our input for the inventory data and abatement costs that were used to generate the emission scenarios analysed in this study.

\subsection{BC mitigation options}

While all efforts to improve combustion efficiency (e.g. improved cook stoves, pellet stoves and boilers) will result in a reduction of $\mathrm{BC}$ and $\mathrm{OC}$ emissions, end-of-pipe options like particle traps for road and off-road diesel engines can also lead to significant reductions of primary carbonaceous particle emissions. Although large-scale industrial combustion is not a major source of BC and OC (even if in some regions it still is major contributor to the PM emissions), and further abatement of PM is of little relevance for these species, some industrial sources represent a potential target for abatement, particularly in some regions. Examples would include small-scale 'village' coke ovens (still operating in China) and traditional brick kilns (still very popular in India). Cleaner technologies exist, but their wider introduction will take time. More detailed characteristics of the above options, including their BC and OC efficiencies, are provided in Kupiainen and Klimont (2004, 2007) and Bond et al. (2004). Furthermore, Bond and Sun (2005) discuss the $\mathrm{BC}$ emissions and RF reduction potential for key $\mathrm{BC}$ abatement measures.

In the analysed scenarios of this study, emission reductions are achieved primarily via end-of-pipe and retrofitting measures (referred to as 'technical'), which have been the mainstay of air pollution control in recent decades. Fuel switching, for example, from coal to oil and gas, however, may in some regions be more important in determining future reductions in $\mathrm{BC}$ emissions than end-of-pipe options (Streets et al., 2004), specifically for residential combustion. In the model we have used, fuel switching 
Table 1. Projected emissions from contained combustion in world regions 2030 in $\mathrm{kt}^{-1}$

\begin{tabular}{|c|c|c|c|c|c|}
\hline & \multicolumn{2}{|c|}{$\mathrm{BC}$} & \multicolumn{2}{|c|}{ OC } & \multirow{2}{*}{$\begin{array}{c}\text { PM }_{10} \text { abated } \\
\text { between CLE and MFTR }\end{array}$} \\
\hline & CLE & MFTR & CLE & MFTR & \\
\hline EU17 & 173 & 125 & 223 & 175 & 243 \\
\hline Rest of Europe (RoE) & 104 & 41 & 136 & 78 & 549 \\
\hline Africa (AFR) & 542 & 403 & 1535 & 1432 & 1602 \\
\hline Centrally Planned Asia (CPA) & 1474 & 1089 & 1994 & 1720 & 26679 \\
\hline East Asia (EAS) & 490 & 360 & 809 & 520 & 2504 \\
\hline South Asia (SAS) & 685 & 458 & 1017 & 895 & 7380 \\
\hline Middle East (MIDE) & 42 & 9 & 43 & 23 & 93 \\
\hline North America (NAM) & 200 & 133 & 271 & 214 & 397 \\
\hline Latin America (LAM) & 233 & 87 & 361 & 247 & 897 \\
\hline Russia (RUS) & 175 & 98 & 102 & 34 & 1517 \\
\hline Japan (JPN) & 26 & 11 & 41 & 34 & 61 \\
\hline Pacific OECD (POE) & 54 & 18 & 56 & 41 & 114 \\
\hline World & 4197 & 2831 & 6586 & 5413 & 42036 \\
\hline
\end{tabular}

Source: RAINS model, Cofala et al. (2007), own calculations.

is not considered, and the maximum feasible technical reduction (MFTR) of emissions relates to a given fuel mix.

\subsection{Emission inventory data}

Emission data for contained sources of primary carbonaceous aerosols originate, in this study, from the global assessment of Cofala et al. (2007). The regional and sectoral data are available from a dedicated website. ${ }^{2}$ These estimates were prepared with the RAINS model (http://www.iiasa.ac.at/rains), specifically using the $\mathrm{BC}$ and $\mathrm{OC}$ module documented in Kupiainen and Klimont (2004, 2007). More detailed data for Europe (excluding Russia) is available from the online version of the model. ${ }^{3}$

$\mathrm{BC}$ emissions from gas and oil flaring for Europe (excluding Russia) are also taken from the RAINS online model. Flaring $\mathrm{BC}$ emissions for the remainder of the regions were extrapolated from projected global natural gas production until 2030 from EIA (2007) and broad assumptions about the distribution of production between regions.

The baseline BC emission scenario (CLE) for 2030 assumes implementation of the current (as of the end of 2004) national and international air pollution legislation resulting in country specific reduction strategies (Cofala et al., 2007). For projections, it is assumed that the technical abatement measures will be installed in a timely manner to comply with the law. This might be an optimistic assumption, especially for the developing countries,

\footnotetext{
${ }^{2}$ http://www.iiasa.ac.at/rains/Glob_emiss/global_emiss.html.

${ }^{3}$ http://www.iiasa.ac.at/web-apps/tap/RainsWeb/; version and scenario used: 'Nov 04' and 'CP_CLE_Aug04' Access to BC and OC data available upon request.
}

bearing in mind some past failures in enforcement even in the developed world. As in Cofala et al. (2007), we assume that in the long term the full compliance will be achieved.

More than a third of global BC emissions from contained combustion originate from CPA (where China is most important), followed by SAS (dominated by India) (Cofala et al., 2007), see Table 1. For OC, the same regions dominate, but in addition AFR is almost as important as CPA. In Africa and Asia, domestic combustion is the dominant source of emissions for both BC and OC. In EU17 and NAM, transport sources are equally important as domestic combustion. For anthropogenic sources of $\mathrm{BC}$, considered in this work, the base year estimates are comparable to Bond et al. (2004). The differences are mainly linked to activity data, especially biofuel use, since RAINS relied on the available national statistics rather than IEA. There are also differences in emission factors since Cofala et al. drew on Kupiainen and Klimont (2007) who developed them to match the RAINS structure. At the global level the estimates used in this study are about $10 \%$ higher than Bond et al. (2004), more discussion is available in Cofala et al. (2007).

In the CLE scenario, BC emissions in the EU are cut in half from current levels by 2030 (Cofala et al., 2007), with reductions expected primarily in transport and domestic sector. Smaller reductions are projected in other regions, and emissions in RUS and AFR increase. Future global emissions of OC are projected to decline owing to assumptions about gradual improvements in the efficiency of stoves and reduced solid fuel (specifically biomass) use in domestic sector. The largest reductions are estimated for China, India and Latin America. Only emissions in Russia (and Middle East) are expected to increase. The MFTR scenario illustrates a further technical potential for reductions in 
all regions. The potential is largest in the developing world with the transport sector being most important for $\mathrm{BC}$ and domestic combustion for OC reductions.

\subsection{Mitigation costs}

In the scenarios, a reduction in RF is obtained by reducing emissions from the CLE to the MFTR emission level along a marginal abatement cost (MAC) curve. A detailed MAC curve has been developed for each of our 12 regions to describe the technical abatement steps (and costs) of reducing BC (and its associated OC) from each region's CLE level. The MAC curve embodies the MFTR level, which is the greatest extent commercially available technologies, can be diffused into use, and thus does not allow BC emissions to fall to zero in each sector and region. The MAC curves for Europe are generated by the RAINS model (www.iiasa.ac.at/rains) as used in Amann et al. (2005). Lacking data for the other regions, we make extrapolations from the RAINS data.

2.3.1. Extrapolated cost-curves for the non-European region. The European BC MAC curves are made up of small intervals which indicate the cost of abating an additional tonne of $\mathrm{BC}$ and the amount of abatement (in tonnes BC) that can be achieved by adding a particular (more efficient) control measure. For example, in the context of coal-burning electricity plants, the intervals could represent the sequential installation of wet scrubbers, fabric filters, and electrostatic precipitators-each contributing a more effective (yet more expensive) removal of $\mathrm{BC}$.

MAC identifies the cost of abating one additional unit of $\mathrm{BC}$ with the addition of a control technology - typically given in units of $€ /$ tBC abated. Detailed discussion and examples for specific sectors and technologies can be found in Klimont et al. (2002).

For example, the MAC of abating BC via the installation of technology $m$ (and the removal of technology $m-1$ ) is calculated as

$M A C_{m}=\frac{U C^{m *} R E^{m}-U C^{m-1 *} R E^{m-1}}{R E^{m}-R E^{m-1}}$,

where $U C$ is the unit cost of each technology versus no control and $R E$ represents the removal efficiency fraction of each technology. Made up of annualized investment costs and annual operation and maintenance expenditures, both unit and MACs are on a yearly basis. Application of technologies is sequential, and technology $m$ may be replaced by $m+1$ and so forth.

Additional emissions removed with technology $M$ is calculated as

$A(m, m-1)=\left(R E^{m}-R E^{m-1}\right)^{*} A C T^{*} E F_{\text {unabated }}$,

where $A(m, m-1)$ is the emissions reduction when switching from existing to the new control technology. $A C T$ is the activity level of the sector, and $E F_{\text {unabated }}$ is the unabated (no control) emissions factor for the relevant sector/activity. Activity units in RAINS are typically given in PJ energy use, Mt production, or $\mathrm{km}$ travelled, with emissions factors in tonnes per activity unit.

For the non-European regions, detailed information required to create a MAC curve is not available. As a result, the information from the EU17 and RoE MAC curves were used to approximate curves through extrapolations. This requires a number of simplifying assumptions. Across countries/regions with similar characteristics and levels of development (i.e. EU17 and USA) it is assumed that the list of technologies, emission factors (EF), removal efficiencies (RE) and unit costs (UC) are the same at a certain level of aggregation.

Each interval of the source (i.e. EU17 or RoE) MAC curve is extrapolated individually to the destination (i.e. NAM or CPA) MAC curve. The source MAC curves for mapping between regions is shown in Table 2. Our assumptions mean that the marginal costs of each interval (€/tonne BC) are equal in both the source and destination countries, as all the elements in eq. (1) are unchanged. The amount of abatement at each interval is different in each region; however, it is only the activity level

Table 2. Source MAC curves used to extrapolate MAC curves

\begin{tabular}{lccc}
\hline Region & Power plants & Road transport & Other sources \\
\hline RUS & RAINS (RUS West) & RAINS (RUS West) & RAINS (RUS West) \\
NAM & EU17 & EU17 & EU17 \\
LAM & Ukraine/RUS (West) & Ukraine & Ukraine \\
EAS & Ukraine/RUS (West) & Unabated, Euro 2 by 2010 & Ukraine \\
CPA & Ukraine/RUS (West) & Unabated, Euro 2 by 2010 & Ukraine \\
SAS & Ukraine/RUS (West) & Unabated, Euro 1 by 2010 & Unabated \\
POE and JPN & EU17 & Poland & EU17 \\
AFR and MIDE & Ukraine/RUS (West) & Unabated & Unabated \\
\hline
\end{tabular}

Notes: Italics denote that data were extrapolated from that region/country. EU17 and RoE MAC curves were derived directly from RAINS data. 


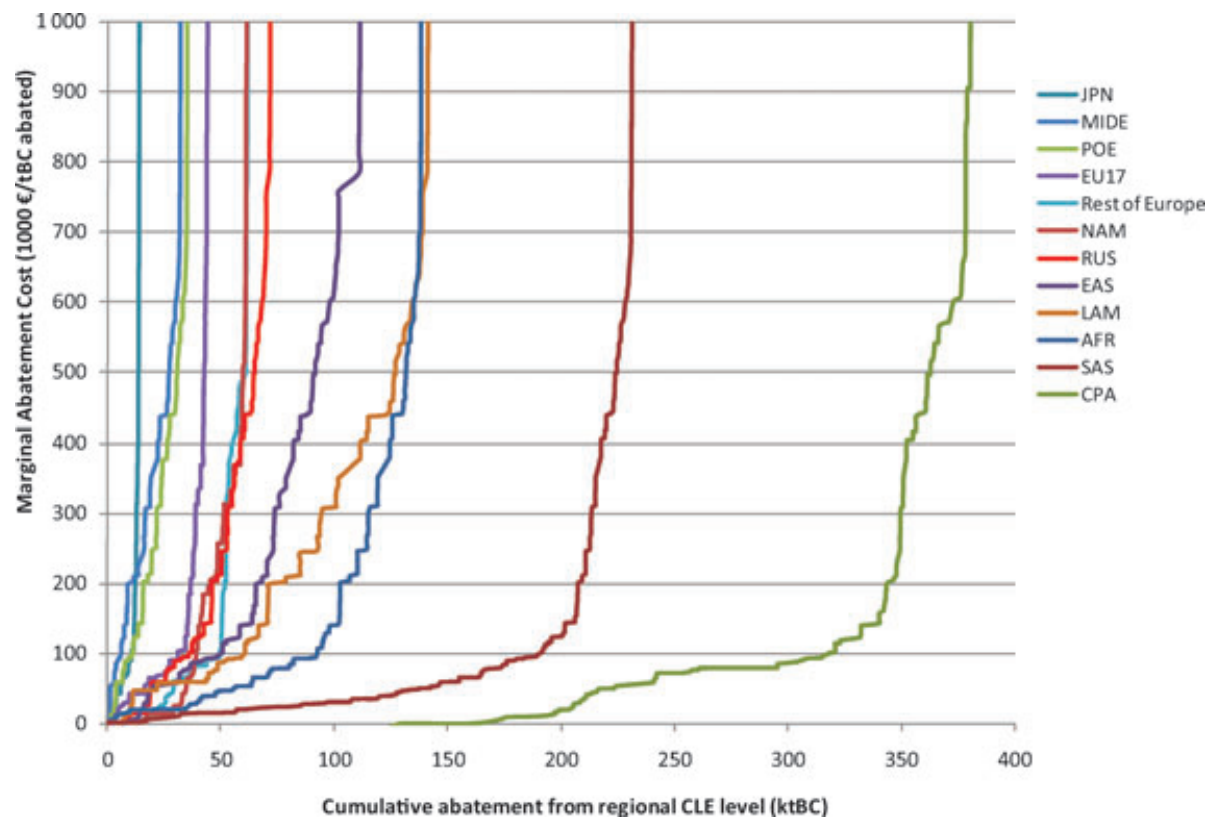

Fig. 1. BC MAC curves for different regions.

(ACT) that contributes to the difference (see eq. (2)). As such, the extrapolation only requires a comparison between the sector activity levels in the source and destination countries. However, because of our assumptions, we can instead use a comparison between the CLE emissions levels (see eq. 3 below).

We divide up the CLE emissions into 10 sectors $^{4}$ and 8 activities/fuels, ${ }^{5}$ yielding up to 40 individual categories (for example, Coal in Power Plants) and undertake an extrapolation at each sector-activity pair.

The abatement quantity for each interval of the MAC curve is extrapolated using the source and destination CLE emissions for the category it belongs to. Such an approach aims to account for the bottom-up differences in each region.

$A(m, m-1)_{\mathrm{dest}}^{i, j}=A(m, m-1)_{\text {source }}^{i, j}\left(\frac{E M(i, j)_{\mathrm{dest}}^{\mathrm{CLE}}}{\operatorname{EM}(i, j)_{\mathrm{source}}^{\mathrm{CLE}}}\right)$,

where $A(m, m-1)$ is the achieved reduction when switching from existing $(m-1)$ to newer $(m)$ control technology. Indexes $i$ and $j$ represent the sector and activity category in which this switch takes place. $E M(i, j)^{\mathrm{CLE}}$ represents the total CLE emissions in each $(i, j)$ category in either the source or destination country.

The results of the extrapolation are detailed MAC sectorlevel curves for each emitting activity for each region. These are aggregated and sorted to generate a single MAC curve for each region, see Fig. 1.

\footnotetext{
${ }^{4}$ Domestic fireplaces and stoves, domestic boilers, industrial processes, other industry, light road, heavy road, water transport, air transport, power plants, rail transport.

${ }^{5}$ Coal, other solid fuels, diesel, gasoline, gas, heavy fuel oil, other liquid and non-fuel.
}

For the purpose of comparison, we combine the regional BC MAC curves into a single global curve (ranked by MAC) to see how the abatement options from each sector and each region contribute towards the global MFTR abatement level. Histograms in Figs. 2 and 3 illustrate the quantity of abatement each activity type and region, respectively, contributes to each quartile of the MFTR abatement.

In the regional histogram (Fig. 3), we see that CPA and SAS dominate the abatement contributions, particularly in the first and second quartiles-suggesting that they offer the cheapest and most plentiful options. The other two key developing regions-LAM and AFR - make notable contributions in the first two quartiles as well. In the activity histogram (Fig. 2), we see that the overall global abatement is dominated by transport abatement options. However, these are not the cheapest choices, and thus the first quartile is dominated by abatement in industrial process activities.

It is worth noting the uncertainties. The extrapolation approach is, of course, undertaken due to the lack of detailed region-specific data on technology availability and costs. While this is justified for practical reasons, and other studies have taken a similar route (Bond and Sun, 2005), we must accept that the MACs are consequently accompanied by several uncertainties beyond those of the original RAINS data.

By assuming that the MACs of each abatement option are the same across the extrapolated regions, we are assuming that the labour, capital, energy, and other components to the options are also the same. We have tried to match appropriately similar countries for the extrapolation, but given that Europe is our source for costs, it is likely that we have overestimated the costs for Africa, South America and Asia. 

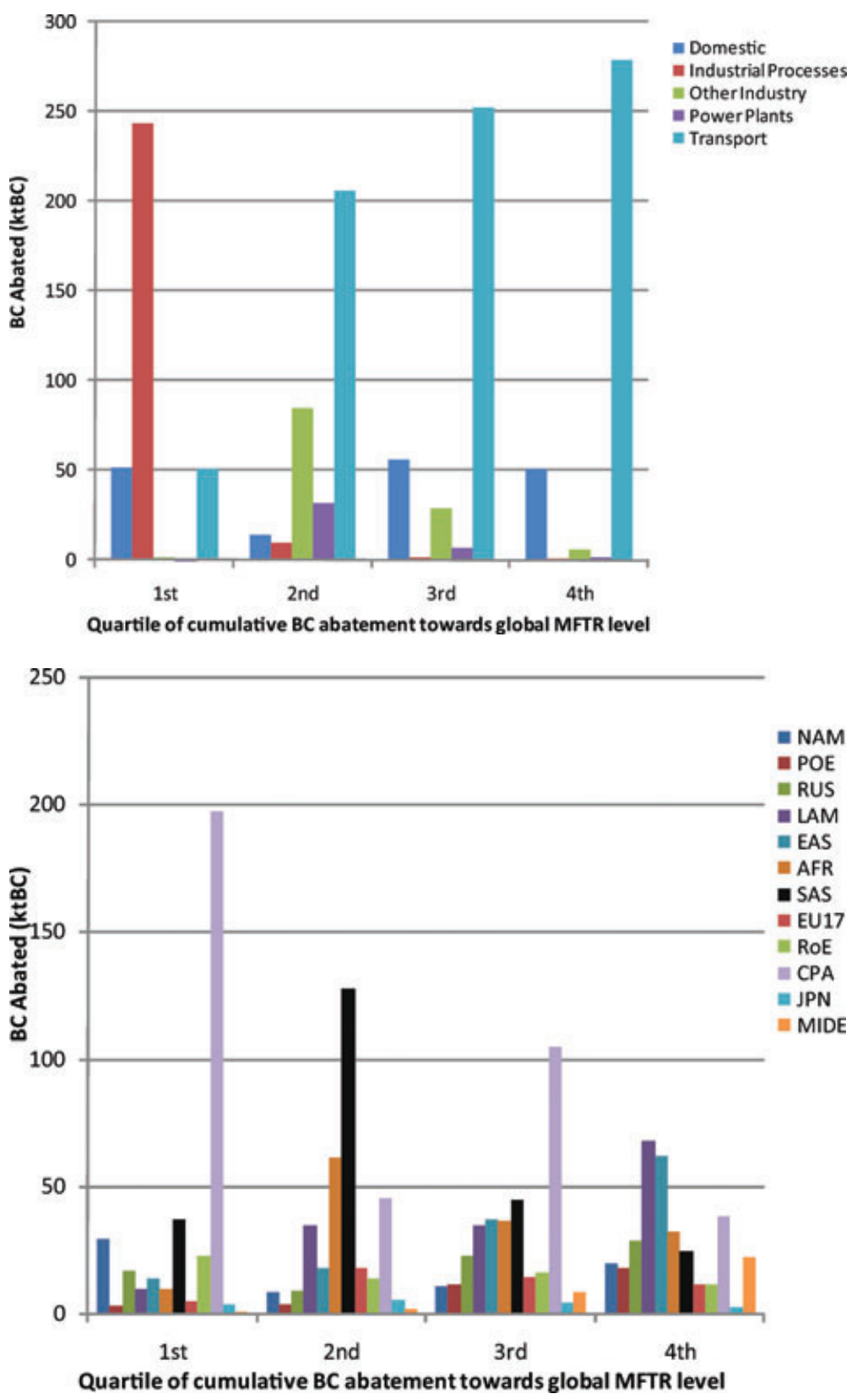

Fig. 2. Abatement contributions (in ktBC) from each activity towards each quartile of global BC MAC curve to MFTR level. Ordered by cost, the abatement options in the first Quartile are cheaper than those in the second, and so on.
In future work, we will seek regional-specific parameters to calculate the regional marginal abatement curves. Regional energy and labour cost data could be used, and are easy to obtain. However, they make up only a small part of the total cost of abatement - the capital costs of construction and maintenance are by far the largest component ( $\sim 50-75 \%$, see Klimont et al., 2002) and are more difficult to obtain. On one hand, technology types will be similar across countries, but domestic variants are likely to vary in price and availability.

It is worth noting, however, that the impact of the uncertainties on our broad results will be mitigated by the notable differences in global warming potential (GWP) values for BC and OC (see next section). These GWP values influence the consequent costeffectiveness of each abatement option, and differences between regions will reduce the impact of technology uncertainties. Thus, while the MAC of each abatement option may change, its costeffectiveness rank relative to other abatement options may stay the same.

We also assume that the quantity abated by each abatement option in each interval is proportional to the total emissions in each country, and that the MFTR to CLE ratio can also be extrapolated. This is particularly prone to uncertainty, because the MFTR level is based not only on the technical capacity of each abatement option, but the socio-economic circumstances 
that allow for its use. Given that EU17 has a particularly strong tradition of air quality control, it is likely that we have overestimated the MFTR to CLE ratio for AFR, LAM and the Asian regions. However, our analysis is for 2030, by which time much could change in these regions. Between these two uncertainties, it is likely that a more rigorous region-specific analysis will shift the MAC curves in Fig. 1 leftward and downward. These directions actually have opposite effects on the overall results, because they make abatement opportunities from the developing countries cheaper-but less plentiful. The net effect is difficult to gauge without further analysis.

\section{Weighting of climate effects: GWPs}

The RF impact of BC emissions across countries is compared using region-specific GWPs [i.e. the ratio of the time-integrated $\mathrm{RF}$ of a unit mass pulse emission and the corresponding timeintegrated RF of a unit mass pulse emission of $\mathrm{CO}_{2}$ (Forster et al., 2007)], which has been established as the tool for comparing climate effects of emissions of different long-lived greenhouse gases (e.g. $\mathrm{CH}_{4}, \mathrm{~N}_{2} \mathrm{O}$ and HFCs). GWPs can also be calculated for short-lived species like BC particles or ozone precursors (e.g. Berntsen et al., 2005; Bond and Sun, 2005; Reddy and Boucher, 2007).

However, GWPs and their application for short-lived species are controversial for several reasons. First, it is not obvious that integrated RF over a long time period (e.g. $100 \mathrm{yr}$ as used in the Kyoto Protocol) is appropriate for evaluating the effects of pulse emissions of short-lived species for which the warming will be virtually zero after a few decades (O' Neill, 2000). Second, the GWP values of short-lived species will depend on the region of emission, as the region affects the lifetime and radiative efficiency (RF per unit change in concentration) (Berntsen et al., 2006; Reddy and Boucher, 2007). Third, even if two regions had equal GWP values from BC, they may have a very different climate impact, even in terms of global mean temperature change, due to differences in climate efficacies (Hansen et al., 2005).

For this study, the first issue is not directly relevant since our starting point is mitigation that targets BC emissions: We consider different $\mathrm{BC}$ mitigation options, and do not attempt to compare them with options that target other climate agents. Should a comparison between the costs of a BC mitigation strategy with other strategies focusing on long-lived GHGs become relevant, then the issue of time horizon becomes important. However, since the RF of $\mathrm{BC}$ becomes virtually zero on a time scale of less than a year, the GWPs of BC for shorter time horizons can be derived by scaling the $\mathrm{GWP}_{100}$ values with the ratio of the absolute GWPs for $\mathrm{CO}_{2}$. For example $\mathrm{GWP}_{20}$ for $\mathrm{BC}$ can be derived by multiplying the $\mathrm{GWP}_{100}$ values with a factor of 3.5.

The second issue, the regional difference in GWPs, is a key issue in this study. We use the global aerosol transport model Oslo CTM2 (Berglen et al., 2004; Berntsen et al., 2006; Myhre et al., 2009) to simulate $\mathrm{BC}$ from the 12 specified regions con- sidered in this study. The Oslo CTM2 is an off-line transport model that uses meteorological data from European Centre for Medium range Weather Forecast (ECMWF). In this study a spatial resolution of $1^{\circ} \times 1^{\circ}$ and 40 vertical layers have been used. The scheme for BC and OC includes hydrophilic and hydrophobic particles, as well as emissions from fossil fuel, biofuel, and open biomass burning (Berntsen et al., 2006; Myhre et al., 2009). For the GWPs for BC, only emissions from fossil and biofuel are considered, with emission data from Bond et al. (2004). The mixing state of BC is important with respect to the absorption and thus the RF (Bond et al., 2006; Fuller et al., 1999). We adopt a method to include internal mixture as suggested by Bond et al. (2006). This method considers only internal mixture of the hydrophilic BC particles and thus an external mixing of the hydrophobic particles. The absorption of the hydrophilic BC particles is increased by $50 \%$ to account for the enhanced absorption by the coated particles. In the radiative transfer calculations, other aerosol types such as sea salt, mineral dust, sulphate, nitrate, and $\mathrm{OC}$ are included because the scattering from other aerosols enhance the absorption by the BC aerosols.

The RF for the direct effect of BC from all fossil and biofuel sources is $0.34 \mathrm{Wm}^{-2}$ giving a global mean GWP of 830 for a $100-y r$ time horizon. The anthropogenic burden of BC is $0.20 \mathrm{mg} \mathrm{m}^{-2}$ from fossil and biofuel. Previously published global mean GWPs for BC is about 25 and $40 \%$ lower (Bond and Sun, 2005; Reddy and Boucher, 2007). Table 3 gives the regional GWP values applied for establishing the mitigation scenarios and range from 640 to 1130 for the direct effect of BC. Most of the regional differences in GWP are caused by differences in the lifetime of $\mathrm{BC}$, although up to $20 \%$ can be explained by differences in the RF per unit mass BC. Figure 4 shows the direct aerosol effect of $\mathrm{BC}$ from fossil and biofuel for the 12 different regions as well as the total direct aerosol effect of BC with emission from all regions. The results from Oslo CTM2 show that regions vary significantly with respect to their pattern of BC RF, and the forcing is localized with respect to the emissions. It is relatively few regions (RUS, EU17, ROE, NAM and CPA) that contribute to the direct aerosol effect forcing of $\mathrm{BC}$ in the Arctic region.

A module for deposition and accumulation of BC in snow has been added to the Oslo CTM2. The module accounts for up to 10 vertical snow layers, and total snow depth is calculated according to snow fall, snow melt and snow sublimation in accordance with the meteorological input data from the ECMWF. During periods without new snowfall, dry deposition will contribute to $\mathrm{BC}$ in the surface layer. This is accounted for by treating a top-layer of $1 \mathrm{ml}$ water equivalent separately. The effect of melting and sublimation is treated relatively simple as it is assumed to take place from the top of the snowpack, and when the whole snowlayer has melted its BC content is added to the layer below. Thus any possible vertical movement of BC in the snowpack by drainage or sedimentation is neglected. Total $\mathrm{BC}$ burden in 
Table 3. Regional GWPs and GTPs for BC (as derived in this study) and OC [derived from Berntsen et al. (2006) and Koch et al. (2007)] used to optimize emission reductions

\begin{tabular}{|c|c|c|c|c|c|c|c|c|}
\hline \multirow[b]{3}{*}{ Regions } & \multicolumn{3}{|c|}{100 yr GWP } & \multirow{3}{*}{$\begin{array}{c}\text { OC } \\
\text { Direct }\end{array}$} & \multicolumn{3}{|c|}{20 yr GWP } & \multirow{3}{*}{$\begin{array}{c}\text { OC } \\
\text { Direct }\end{array}$} \\
\hline & \multicolumn{3}{|c|}{$\mathrm{BC}$} & & \multicolumn{3}{|c|}{$\mathrm{BC}$} & \\
\hline & Direct & Indirect albedo & Total & & Direct & Indirect albedo & Total & \\
\hline EU17 & 720 & 110 & 830 & 0 & 2500 & 390 & 2900 & 0 \\
\hline RoE & 720 & 160 & 880 & 0 & 2500 & 560 & 3100 & 0 \\
\hline RUS & 640 & 190 & 830 & 0 & 2300 & 670 & 2900 & 0 \\
\hline NAM & 720 & 110 & 830 & -43 & 2500 & 390 & 2900 & -150 \\
\hline LAM & 940 & 10 & 950 & -72 & 3300 & 35 & 3300 & -250 \\
\hline EAS & 980 & 10 & 990 & -58 & 3400 & 35 & 3500 & -200 \\
\hline $\mathrm{CPA}$ & 710 & 40 & 750 & -58 & 2500 & 140 & 2600 & -200 \\
\hline SAS & 1040 & 70 & 1110 & -58 & 3700 & 250 & 3900 & -290 \\
\hline JPN & 640 & 90 & 730 & -82 & 2300 & 320 & 2600 & -200 \\
\hline POE & 670 & 30 & 700 & -82 & 2400 & 110 & 2500 & -290 \\
\hline AFR & 1130 & 10 & 1140 & -54 & 4000 & 35 & 4000 & -190 \\
\hline \multirow[t]{3}{*}{ MIDE } & 1100 & 220 & 1320 & -28 & 3900 & 770 & 4600 & -100 \\
\hline & \multicolumn{3}{|c|}{100 yr GTP } & & \multicolumn{3}{|c|}{20 yr GTP } & \\
\hline & \multicolumn{3}{|c|}{$\mathrm{BC}$} & OC & \multicolumn{3}{|c|}{$\mathrm{BC}$} & OC \\
\hline Regions & Direct & Indirect albedo & Total & Direct & Direct & Indirect albedo & Total & Direct \\
\hline EU17 & 53 & 9 & 62 & 0 & 250 & 41 & 290 & 0 \\
\hline RoE & 53 & 12 & 65 & 0 & 250 & 56 & 300 & 0 \\
\hline RUS & 47 & 19 & 65 & 0 & 220 & 88 & 310 & 0 \\
\hline NAM & 53 & 9 & 62 & -5 & 250 & 43 & 290 & -40 \\
\hline LAM & 69 & 2 & 71 & -9 & 330 & 84 & 330 & -66 \\
\hline EAS & 72 & 2 & 74 & -9 & 340 & 11 & 350 & -62 \\
\hline $\mathrm{CPA}$ & 52 & 3 & 55 & -9 & 240 & 14 & 260 & -62 \\
\hline SAS & 76 & 5 & 81 & -12 & 360 & 21 & 380 & -84 \\
\hline JPN & 47 & 8 & 55 & -9 & 220 & 38 & 260 & -62 \\
\hline POE & 49 & 8 & 57 & -12 & 230 & 40 & 270 & -84 \\
\hline AFR & 83 & 2 & 85 & -7 & 390 & 8.7 & 400 & -49 \\
\hline MIDE & 81 & 14 & 95 & -4 & 380 & 67 & 440 & -25 \\
\hline
\end{tabular}

snow (including contribution from biomass burning) at the end of April is given in Fig. 5. The RF due to BC in snow is based on pre-calculated lookup tables for the relation between $\mathrm{BC}$ concentration in snow and ice and surface albedo. The lookup tables are calculated with a radiative transfer code (Stamnes et al., 1988) and with BC optical properties as suggested in (Bond et al., 2006) including an enhancement in the absorption to take into account internal mixture as coated $\mathrm{BC}$ particles. The 10 snow layers in the CTM2 model are reduced to two snow layers in the radiative transfer calculations with $1 \mathrm{~mm}$ water equivalent thickness of the upper layer. The calculations of the lookup tables of surface albedo are performed with 33 atmospheric layers in addition to the two snow layers. In these calculations an effective snow grain size of $500 \mu \mathrm{m}$ is adopted. Sensitivity calculations show an uncertainty of $25 \%$ related to the snow grain size. The $\mathrm{BC}$ has a larger effect on the surface albedo for larger snow grain sizes for a given snow layer (Flanner et al., 2007). However, larger snow grain sizes reduce the impact of the upper snow layer due to deeper penetration of the solar radiation in the snow, and the upper layer has often a higher BC concentration. Therefore, the uncertainty of the snow grain size of $25 \%$ is similar or smaller than their factors influencing this RF mechanism. Global calculations are performed with an off-line radiative transfer code for global conditions (Myhre et al., 2007). The RF results are presented for annual means and are based on calculations with a 3-hr step. The BC impact on the snow albedo is non-linear with strongest impact at small abundances (Flanner et al., 2007). In our RF calculations we have first calculated the contribution from each region, that is, with no $\mathrm{BC}$ emissions from other regions. To take into account the non-linearity in the $\mathrm{BC}$ on snow albedo we thereafter calculated the total RF in a simulation with $\mathrm{BC}$ emissions from all regions included. The RF from each region was obtained by scaling the results for each region to this total. 

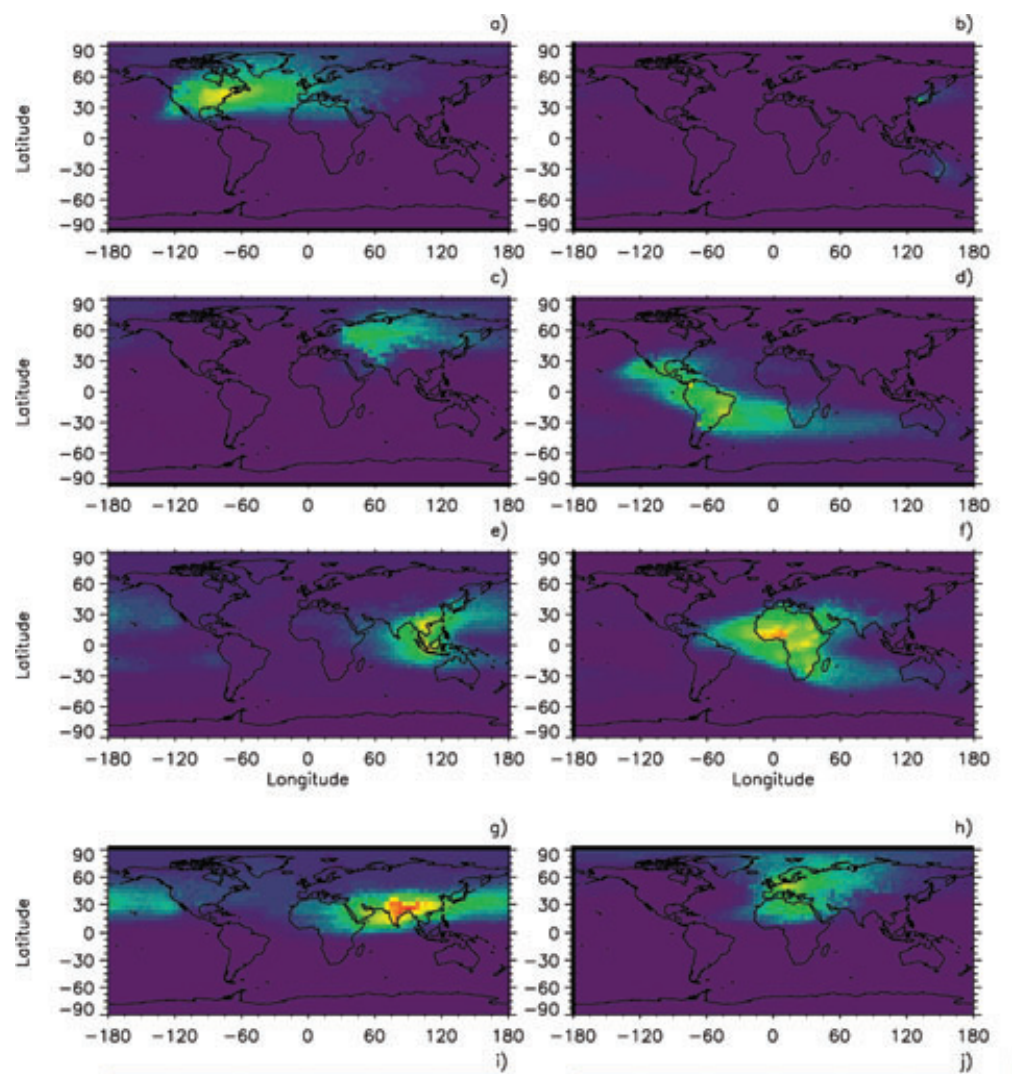

$\mathrm{W} \mathrm{m}^{-2}$
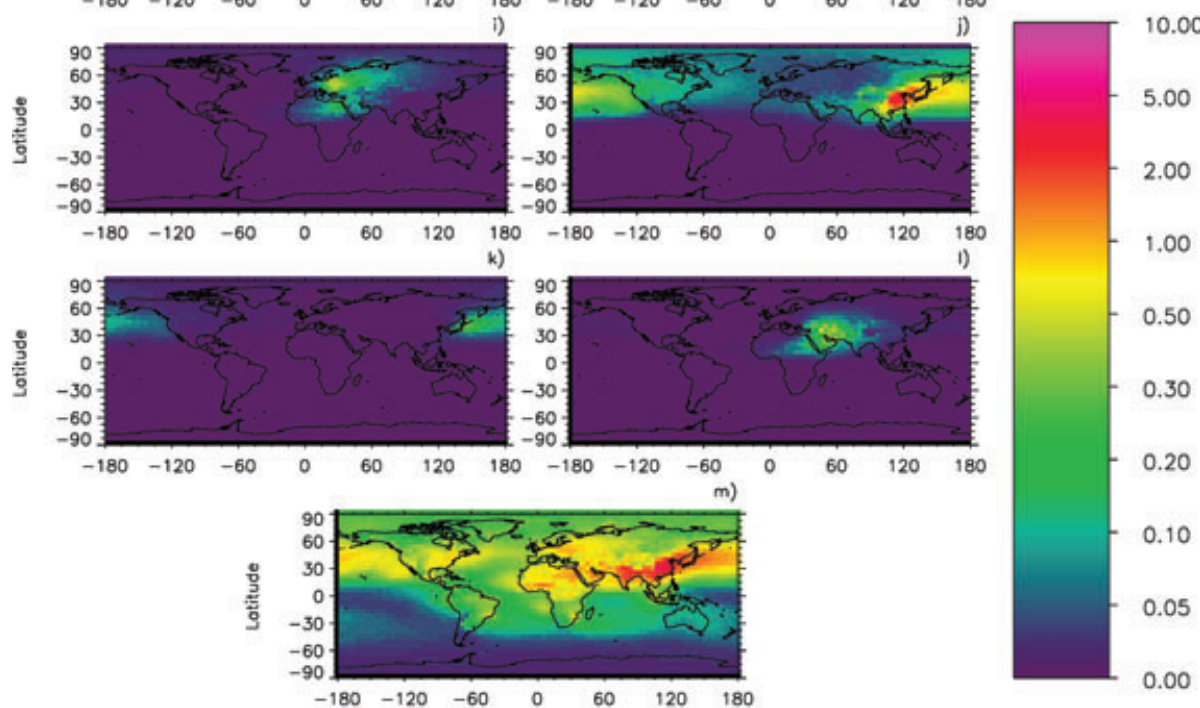

Fig. 4. Radiative forcing of the direct aerosol effect of BC from fossil and biofuel of emissions from: (a) NAM; (b) POE; (c) RUS; (d) LAM; (e) EAS; (f) AFR; (g) SAS; (h) EU17; (i) RoE; (j) CPA; (k) JPN; (l) MIDE; (m) all regions.

The global and annual mean RF due to reduced surface albedo caused by BC in snow is calculated to be $0.03 \mathrm{Wm}^{-2}$. Our explicit RF calculation is weaker than Reddy and Boucher (2007) and Hansen and Nazarenko (2004). In Reddy and Boucher (2007) the RF of the BC impact on snow and ice albedo is specified to $0.1 \mathrm{Wm}^{-2}$ based on existing literature. Hansen and Nazarenko (2004) specified surface albedo changes of snow and ice, with larger changes than our model results and a resulting RF that is stronger. We have also a somewhat weaker RF (30\%) than Flanner et al. (2007) with an approach that is rather similar to this study, but with different $\mathrm{BC}$ transport models and radiative transfer schemes.

Figure 6 shows the RF due to $\mathrm{BC}$ impact on snow and ice albedo for emissions for selected regions. The physical-based 


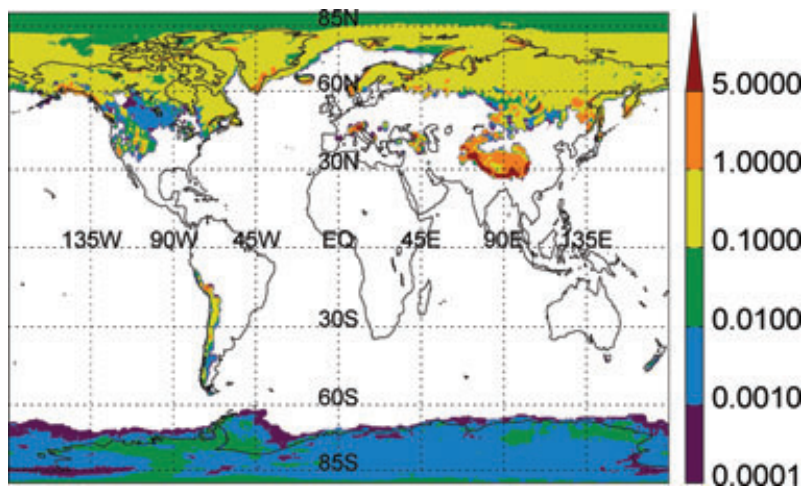

Fig. 5. BC burden $\left(\mathrm{mg} / \mathrm{m}^{2}\right)$ in snow (modelled, end April).

method presented here shows rather homogeneous RF values above $70^{\circ}$ north, some high values over land areas in the northern hemisphere especially at high altitude locations, and very weak values in the southern hemisphere. The contribution to the $\mathrm{BC}$ on snow and ice albedo impact in the Arctic is mainly from emissions from NAM, EU17, RoE, RUS and CPA. However, several regions contribute to significant RF at lower latitudes with generally higher BC concentrations and stronger solar radiation. This is particularly evident for some of the emission regions in Asia. There is a smaller domination of a few emission regions in our results compared to Reddy and Boucher (2007) because their method considered BC deposition only at latitude above $60^{\circ}$. However, our GWP for the BC snow albedo effect has a large range from 10 to 220 (see Table 3 ). The global annual mean estimate is slightly lower than the estimate from Flanner et al. (2007), and significantly lower than the estimate from Hansen and Nazarenko (2004).

The forcing of BC deposited on snow and ice is coincidentally largest with snowmelt onset, triggering strong snow-albedo feedback. Thus simulations in GCMs (Hansen and Nazarenko 2004; Hansen et al., 2005; Flanner et al., 2007) indicate that the 'efficacy' of $\mathrm{BC} /$ snow forcing is two to four times greater than forcing by $\mathrm{CO}_{2}$. A simple way to include this in the analysis is to incorporate the efficacy in the GWP value by multiplying the indirect GWPs in column 3 of Table 3 with an efficacy factor of 3. Since this efficacy factor is very uncertain we have carried out the analysis first without it (i.e. assuming an efficacy factor of 1.0 for all processes) and then as a sensitivity case with an efficacy factor of 3 for BC on snow ( $c f$. Table 3).

The regional GWPs for OC aerosols are based on the average of the RF estimates for regional emissions from Berntsen et al. (2006) and Koch et al. (2007), and the values as given in Table 3 are adopted for the regions used in this study. For the European regions a GWP of zero is assigned to OC because the two studies give RF estimates of similar magnitude but different signs (Koch et al. (2007) estimates a positive RF value for OC from Europe). Due to limitations in data from published model studies, the uncertainties for the OC GWPs applied here are higher than the BC GWPs.

Using the regional RF estimates as for the GWP calculations described above, we have used the alternative global temperature change potential (GTP) emission metric (Shine et al., 2005) and calculated GTPs for BC for time horizons of 20 and 100 yr using a simple analytical two-box climate model (Berntsen and Fuglestvedt, 2008) to derive the GTPs. As for the GWPs the indirect snow albedo values are calculated with a climate efficacy of 1.0. In generating the emission scenarios, only the relative regional differences in metric matters. We note that the different metrics in Table 3 would not imply any difference in this respect, and thus GWP-100 is used in this study.

It should be noted that when we consider the GWP of BC, we do not consider any increase in $\mathrm{CO}_{2}$ emissions that occurs when abatement technology is implemented. The most evident of this is increased energy use required and the carbon leakage varies greatly between sectors and technologies. Conservative rough estimates with GAINS results in increased $\mathrm{CO}_{2}$ emissions of approximately $20 \mathrm{tCO}_{2} / \mathrm{tBC}$ for the EU-17 region and $70 \mathrm{tCO}_{2} / \mathrm{tBC}$ for CPA (excluding transport). Given the GWP estimates of $\mathrm{BC}$ in Table 3, introducing $\mathrm{CO}_{2}$ cross-abatement into our calculations is unlikely to significantly impact our scenario results in terms of optimal technology deployment, except when the GTP-100 is used. Overall climate impact, of course, will be slightly overestimated for non-transport sources. For the GTP100 the metric values for $\mathrm{BC}$ and the increased $\mathrm{CO}_{2}$ emissions per $\mathrm{BC}$ abated are about equal, which means that the net effects of these mitigation measures would be close to zero if the $\mathrm{CO}_{2}$ increase had been included in the GTP-100. However, given the fact that the using the GTP-100 implies that any contributions to climate change between now and $100 \mathrm{yr}$ into the future are considered unimportant, we find it quite unlikely that the GTP metric with such a long time horizon will be used in climate policies.

\section{Scenarios}

We develop scenarios, which assume that a global abatement strategy will seek to maximize reductions in global RF from $\mathrm{BC}$, independent of efforts to reduce other greenhouse gases. However, the contribution from co-abated OC in changing RF is explicitly considered as well. To explore the different roads for abating BC emissions, we developed three main mitigation scenarios.

Scenario 1 (S1): Maximizing RF reductions only

We implement emission reductions in the regions where the $\mathrm{RF}$ reduction per tonne $\mathrm{BC}$ abated is the greatest. We assign region-specific GWP values to $\mathrm{BC}$ to approximate its effect on $\mathrm{RF}$ (climate effect) as described in Section 3. In this scenario, we ignore the cost-effectiveness of control options. 

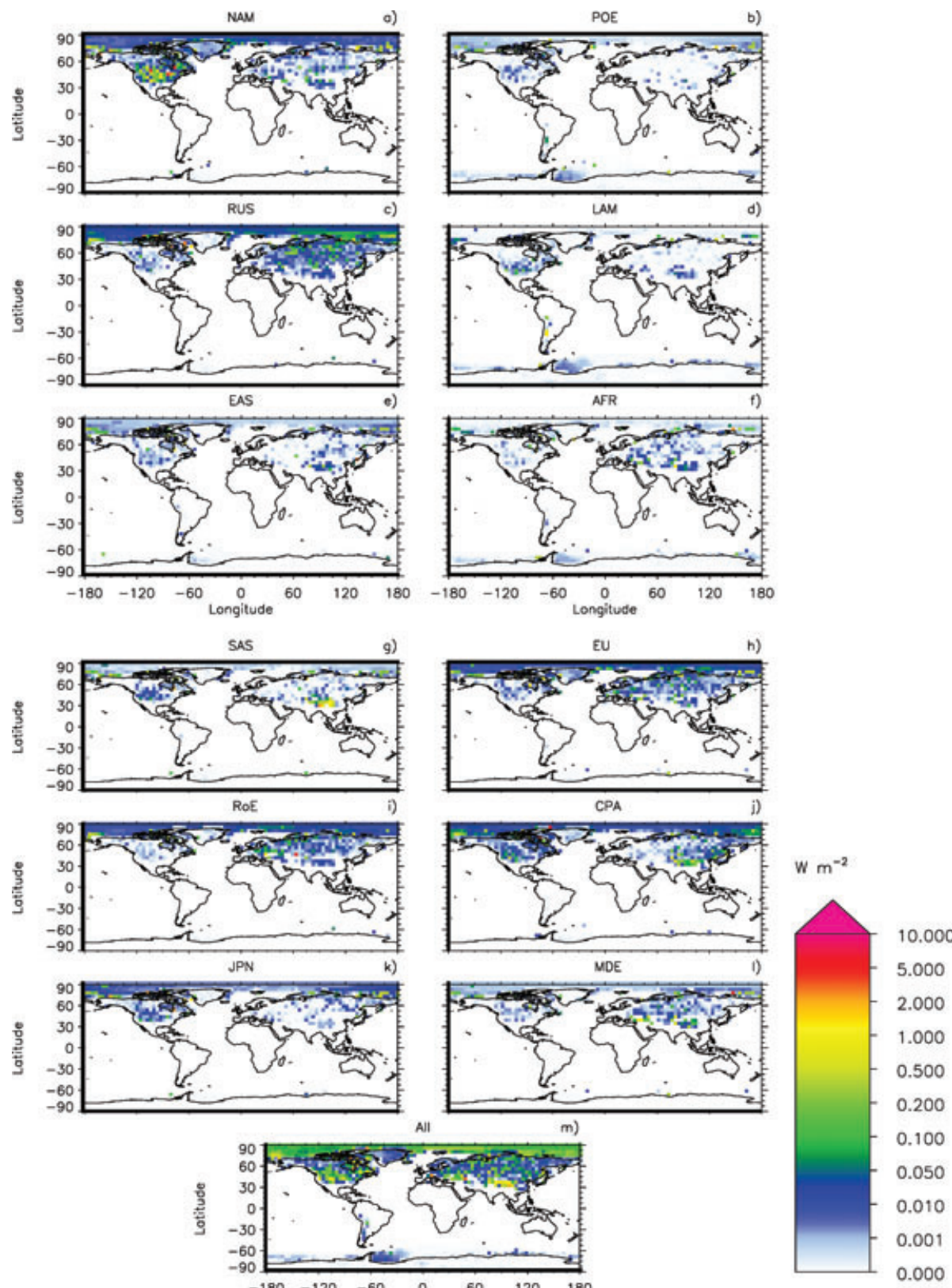

Fig. 6. Radiative forcing of BC impact on snow and ice surface albedo effect for emissions from: (a) NAM; (b) POE; (c) RUS; (d) LAM; (e) EAS; (f) AFR; (g) SAS; (h) EU17; (i) RoE; (j) CPA; (k) JPN; (l) MIDE; (m) all regions.

\section{Scenario 2 (S2): Cost-effectiveness}

Abatement costs differ between regions. For example, since abatement measures targeting PM have already been implemented in Europe and North America, cheaper abatement opportunities may be available in other regions of the world. Emission source and fuel use structure will also determine abatement costs. The inputs to this scenario are the detailed regional MAC curves described in Section 2.3. S2 reflects the cost-effective strategy of reducing emissions first in regions (and sources) where the MACs are the lowest while maximizing the climate benefit; in other words it focuses on maximizing reduced RF per unit cost.

Scenario 3 (S3): Ability to pay

A cost-effective strategy may be difficult to implement globally, as many countries will have limited financial resources and/or face larger political obstacles to efficient implementation of abatement measures. This is manifested in negotiations for international climate agreements wherein developing countries - who may have very cheap GHG reduction opportunities - are excluded from abatement responsibilities 
on the grounds of their ability to pay: 'common but differentiated responsibilities'. We use the gross domestic product (GDP) per capita as a proxy for the ability to pay [as used by e.g. Dinwiddy and Teal (1996)], scaling regional abatement costs linearly by relative GDP per capita. In S3, we thus maximize reduced RF per unit abated weighted by relative GDP per capita. Regional GDP per capita for 2030 was taken from the downscaled SRES database at http://www.ciesin.columbia.edu/datasets/downscaled/.

Finally, we considered each scenario under three different targets: reducing the global BC RF by 10, 20 and $30 \%$, respectively, hereafter named 'RF-10', 'RF-20' and 'RF-30'. We run three versions of all scenarios with respect to the climate effect: one that takes into account the direct climate effect only, a second that also takes into account the indirect effect of BC deposited on snow and a third that considers the enhanced climate efficacy of BC deposited on snow. Thus, altogether 27 different runs have been made. The absolute value of the forcing does not matter in the optimizations, but the consideration of BC deposited on snow implies different regional weights compared to considering the direct effect only. The semi-direct effect is not included in the analysis, as even the global estimates for this are very uncertain.

\section{Results}

The resulting emission reductions are shown in Table 4 for total emissions and in Table 5 and Fig. 7 for regional emissions. Applying all the emission control measures available in the model (MTFR scenario) achieves globally 35\% reduction of BC RF.

In S1, mitigation takes place first in the regions with the highest GWP. Taking into account the direct GWP only, the most effective strategy is to first mitigate in AFR, MIDE and SAS. Even when reducing global RF by $20 \%$ (RF-20), reductions are not implemented in CPA, Europe or RUS. When weighting the climate impact using the total GWP this picture is unchanged. Only when the climate effects are weighted taking on board a higher climate efficacy of BC deposited on snow and ice are emissions in Europe, RUS and CPA abated under RF-20 (RUS already at RF-10). The reductions in $\mathrm{S} 1$ are very expensive, since all abatement potential is exhausted in one region before moving on to the next with a lower benefit in terms of reduced RF per tonne abated. For the case of direct GWP only, the costs of $10 \%$ reduction in $\mathrm{RF}$ (RF-10) are 16 times higher than in S2 (minimizing the costs), while under RF-20 S1 costs are eight times higher.

In S2, where cost-effectiveness across regions is taken into account, the most effective strategy is to introduce reductions first in Asia. If RF is to be reduced by $10 \%$ (direct GWP only), then almost $50 \%$ of the global abatement effort should take place in CPA and $18 \%$ in SAS. With a $20 \%$ reduction in RF, these figures are 31 and $23 \%$, while mitigation efforts in Europe increase from 7 to $8 \%$ of the total global abatement. If total GWP and the climate efficacy are taken into account in the RF20 case, the European reduction burden increases to 9 and $10 \%$, respectively, while for CPA and SAS the burden is 54 and $55 \%$. Consequently, the consideration of the indirect component of the GWP and climate efficacy would not be a very important factor in shifting regional abatement efforts when cost-effectiveness is included in the analysis.

Under S2 (RF-20), the largest share of BC abatement (37\%) should take place in road transport/machinery, followed by industrial processes and domestic boilers (see Fig. 8). The sources abated show small differences between the three versions of the S2 scenario.

RF-10 means that the largest share of BC abatement (56\%) should take place in industrial processes. According to our data,

Table 4. Emission reductions $\left(\mathrm{kt} \mathrm{yr}^{-1}\right)$ and total annual costs (billion $€$ ) for analysed scenarios and reductions in $\mathrm{BC} \mathrm{RF}$

\begin{tabular}{|c|c|c|c|c|c|c|c|c|c|c|c|c|}
\hline & \multicolumn{3}{|c|}{$10 \%$} & \multirow[b]{2}{*}{ Costs } & \multicolumn{3}{|c|}{$20 \%$} & \multirow[b]{2}{*}{ Costs } & \multicolumn{3}{|c|}{$30 \%$} & \multirow[b]{2}{*}{ Costs } \\
\hline & $\mathrm{BC}$ & $\mathrm{OC}$ & $\mathrm{PM}_{10}$ & & $\mathrm{BC}$ & $\mathrm{OC}$ & $\mathrm{PM}_{10}$ & & $\mathrm{BC}$ & $\mathrm{OC}$ & $\mathrm{PM}_{10}$ & \\
\hline \multicolumn{13}{|c|}{ Direct GWP only } \\
\hline $\mathrm{S} 1$ & 310 & 268 & 7254 & 43 & 668 & 649 & 11463 & 196 & 1146 & 1057 & 31039 & 300 \\
\hline S2 & 418 & 357 & 2978 & 3 & 775 & 555 & 11132 & 23 & 1166 & 743 & 35477 & 98 \\
\hline S3 & 450 & 310 & 2667 & 10 & 833 & 584 & 26010 & 43 & 1189 & 803 & 35645 & 120 \\
\hline \multicolumn{13}{|c|}{ Total GWP } \\
\hline $\mathrm{S} 1$ & 310 & 268 & 7254 & 43 & 688 & 683 & 11551 & 214 & 1143 & 1113 & 16129 & 328 \\
\hline $\mathrm{S} 2$ & 416 & 380 & 4113 & 3 & 775 & 556 & 11060 & 23 & 1164 & 747 & 35590 & 97 \\
\hline S3 & 444 & 309 & 2579 & 10 & 829 & 584 & 26001 & 42 & 1183 & 803 & 35669 & 118 \\
\hline \multicolumn{13}{|c|}{ Efficacy } \\
\hline $\mathrm{S} 1$ & 310 & 246 & 8593 & 44 & 661 & 581 & 11797 & 178 & 1121 & 1111 & 15767 & 353 \\
\hline $\mathrm{S} 2$ & 410 & 378 & 4059 & 2 & 769 & 556 & 11129 & 22 & 1153 & 767 & 36446 & 92 \\
\hline S3 & 426 & 307 & 2791 & 9 & 811 & 579 & 25817 & 40 & 1167 & 782 & 35276 & 114 \\
\hline
\end{tabular}




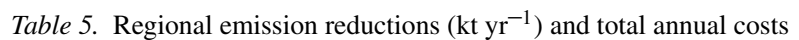
(billion $€$ ) for selected regions under 10 and $20 \%$ reduction in BC RF

\begin{tabular}{|c|c|c|c|c|c|c|c|c|}
\hline & \multicolumn{4}{|c|}{$10 \%$} & \multicolumn{4}{|c|}{$20 \%$} \\
\hline & $\mathrm{BC}$ & $\mathrm{OC}$ & $\mathrm{PM}_{10}$ & Costs & $\mathrm{BC}$ & $\mathrm{OC}$ & $\mathrm{PM}_{10}$ & Cost \\
\hline \multicolumn{9}{|c|}{ EU-17 } \\
\hline \multicolumn{9}{|c|}{ Direct GWP only } \\
\hline S1 & 0 & 0 & 0 & 0 & 0 & 0 & 0 & 0 \\
\hline $\mathrm{S} 2$ & 5 & 2 & 17 & 0 & 27 & 9 & 64 & 1 \\
\hline S3 & 38 & 13 & 96 & 2 & 43 & 21 & 173 & 4 \\
\hline \multicolumn{9}{|c|}{ Total GWP } \\
\hline S1 & 0 & 0 & 0 & 0 & 0 & 0 & 0 & 0 \\
\hline S2 & 5 & 2 & 17 & 0 & 27 & 9 & 65 & 1 \\
\hline S3 & 39 & 14 & 97 & 3 & 43 & 21 & 173 & 4 \\
\hline \multicolumn{9}{|c|}{ Efficacy } \\
\hline $\mathrm{S} 1$ & 0 & 0 & 0 & 0 & 48 & 48 & 243 & 19 \\
\hline $\mathrm{S} 2$ & 5 & 2 & 17 & 0 & 28 & 9 & 66 & 1 \\
\hline S3 & 39 & 14 & 97 & 3 & 44 & 21 & 173 & 5 \\
\hline
\end{tabular}

CPA

\begin{tabular}{ccccccccc}
\multicolumn{2}{l}{ Direct GWP only } & & & & & \\
S1 & 0 & 0 & 0 & 0 & 0 & 0 & 0 & 0 \\
S2 & 199 & 164 & 650 & 0 & 242 & 188 & 2060 & 2 \\
S3 & 210 & 174 & 1040 & 1 & 321 & 230 & 18873 & 9 \\
Total GWP & & & & & & & \\
S1 & 0 & 0 & 0 & 0 & 0 & 0 & 0 & 0 \\
S2 & 199 & 164 & 650 & 0 & 240 & 188 & 1925 & 2 \\
S3 & 209 & 173 & 969 & 1 & 321 & 230 & 18873 & 9 \\
Efficacy & & & & & & & \\
S1 & 0 & 0 & 0 & 0 & 0 & 0 & 0 & 0 \\
S2 & 197 & 164 & 619 & 0 & 240 & 188 & 1916 & 2 \\
S3 & 208 & 170 & 833 & 1 & 308 & 228 & 18853 & 8
\end{tabular}

SAS

\begin{tabular}{ccccccccc}
\multicolumn{7}{c}{ Direct GWP only } & \multicolumn{7}{c}{} & & & & \\
S1 & 137 & 138 & 5559 & 3 & 224 & 174 & 6495 & 24 \\
S2 & 74 & 69 & 1066 & 1 & 182 & 149 & 5470 & 7 \\
S3 & 16 & 12 & 178 & 0 & 99 & 111 & 2765 & 2 \\
\multicolumn{2}{l}{ Total GWP } & & & & & & & \\
S1 & 137 & 138 & 5559 & 3 & 224 & 174 & 6495 & 24 \\
S2 & 76 & 98 & 2328 & 1 & 182 & 149 & 5443 & 7 \\
S3 & 16 & 12 & 178 & 0 & 99 & 111 & 2765 & 2 \\
Efficacy & & & & & & & \\
S1 & 226 & 201 & 7380 & 24 & 226 & 201 & 7380 & 24 \\
S2 & 72 & 96 & 2320 & 1 & 182 & 150 & 5476 & 7 \\
S3 & 18 & 24 & 766 & 0 & 98 & 111 & 2622 & 2 \\
\hline
\end{tabular}

this sector has a large mitigation potential and many low-cost measures. However, we note that both reduction potential and abatement cost rely on scarce information for only few processes (e.g. coking, brick manufacturing), and are therefore very uncertain.
S3, which takes into consideration the ability to pay for reductions (with abatement costs weighted by relative GDP per capita), shifts optimal abatement efforts from SAS and AFR to richer regions (although there is little change or an increase in abatement for China compared to S2). Here, abatement efforts in EU-17, RUS, JPN and NAM should increase by 40-60\% under RF-20 compared to $\mathrm{S} 2$. Total global costs increase by more than a factor of four compared to S2 under RF-10, while they almost double under RF-20.

The $\mathrm{PM}_{10} / \mathrm{BC}$ ratio, which indicates the level of $\mathrm{PM}_{10}$ that is abated along with $\mathrm{BC}$, is the highest for $\mathrm{S} 1$. It depends on the control technologies applied-and the characteristics of these technologies as indicated in the RAINS model. The ratio is also very sensitive to the degree of RF reduction. This is because the global ratio masks substantial interregional variation where the $\mathrm{PM}_{10} / \mathrm{BC}$ reduction ratio is far higher in Africa and EAS compared to other regions for $\mathrm{S} 2$.

Use of the climate efficacy GWP in the optimization gives the overall lowest total costs for all scenarios (except S1), but differences are small. This is because the relatively higher GWP of Europe means that fewer tonnes of $\mathrm{BC}$ need to be abated to achieve a given relative reduction in RF (as shown in our results), and this outweighs the higher cost of European and North American abatement. The minimum total cost of a $30 \%$ reduction in global BC RF from the CLE level is 98 billion $€$. Reducing emissions beyond that would be very costly.

\section{Discussion and conclusions}

Optimizing global abatement of BC at this stage relies on a number of quite uncertain and partly extrapolated data. In order to draw more definite conclusions about efficient global abatement strategies it is important to reduce these uncertainties. Below we highlight some key considerations.

The regional distribution of the climate impact of emitted BC expressed as GWPs is uncertain because it depends on many factors and available studies are very limited. However, the interregional range of the GWPs from this study and from Reddy and Boucher is very similar (about a factor of 1.8 between the region with lowest and highest direct GWP). There are indications in Reddy and Boucher (2007) that the total (direct + snow/albedo) GWP is higher for Europe and northern Eurasia than for other world regions. This result is supported by several studies of the transport pathways into the Arctic (Iversen, 1984; Barrie, 1986; Stohl, 2006). However, Reddy and Boucher (2007) also find that the direct GWPs of developing country regions located at low latitudes like Africa and Latin America are relatively high compared to, for example, Western Europe; this finding is consistent with the results from Berntsen et al. (2005). While also the absolute level of RF from BC is uncertain, this uncertainty does not affect the main results of this study.

While we have region-specific CLE and MFTR emissions data for each of our regions, for lack of data we have used 


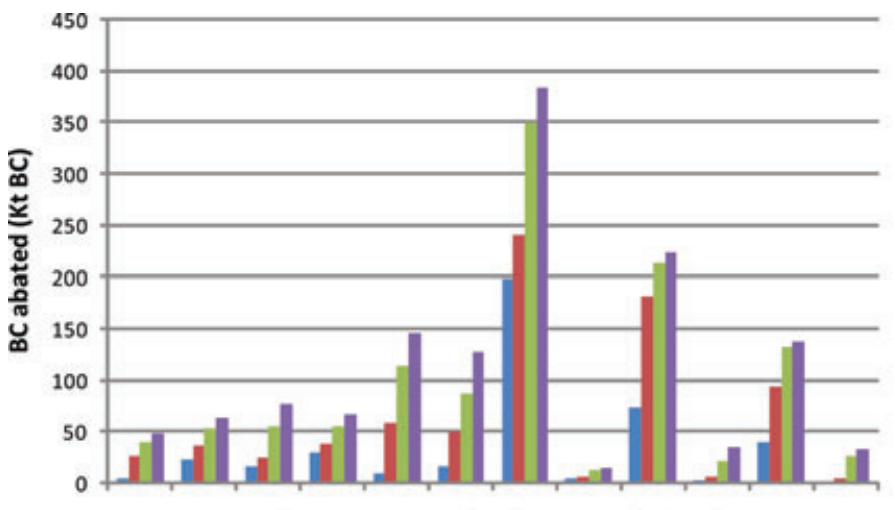

EU 17 RoE RUS NAM LAM EAS CPA JPN SAS POE AFR MIDE

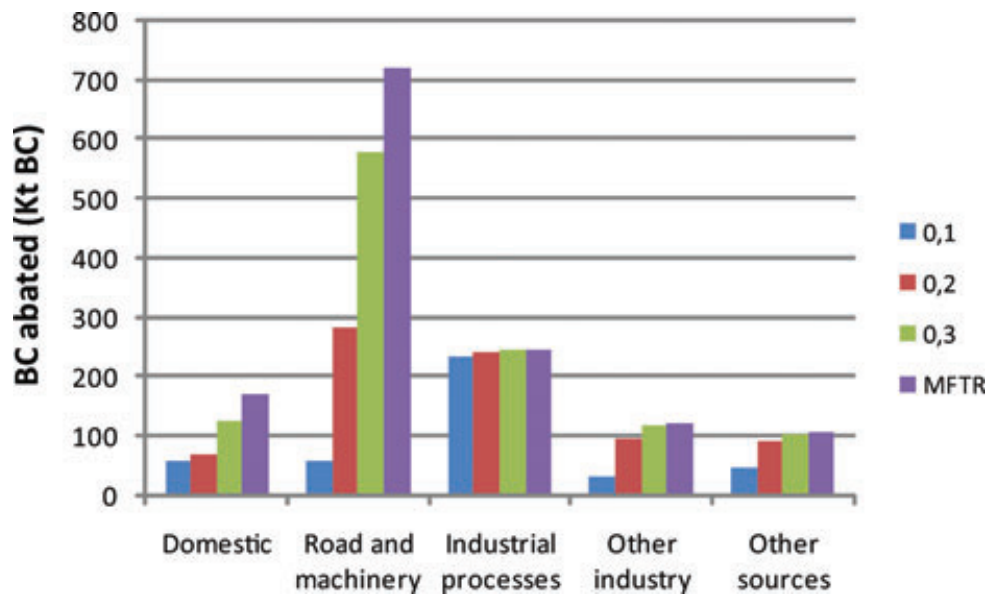

Fig. 7. BC emission reductions (kt) per region under 10, 20 and $30 \%$ reduction in $\mathrm{RF}$ (S2, direct GWP). approximate MAC cost data for the non-European regions. The results build on the assumption that low-cost abatement options are available for developing countries, particularly Asia. Although this is consistent with several other studies for Asia, for example, Streets et al. (2004) and Bond et al. (2004), for other regions, for example, Africa and Latin America, comparable studies are few or missing. The mitigation potential in all these regions is reflected in the emission data Cofala et al. (2007). While the general assumptions made about abatement options and costs in these regions are robust, studies focusing on specific regions and sectors would be needed to further explore the scope and limitations for emission reductions as well as their costs. In particular, information about domestic sector and small-scale industry is often scarce.

Our analysis shows that the optimal strategy from a climate and total global cost perspective is to prioritize abatement of $\mathrm{BC}$ emissions in Asia. Handling of BC reductions from a global climate perspective would, however, require global or regional cooperation to ensure global cost-effectiveness.

Reductions in $\mathrm{BC}$ emissions in Asia seeking to minimize the climate impact also give the highest co-benefits in terms of reduced $\mathrm{PM}_{10}$ emissions. An important question is whether a strategy targeting reductions in RF would give the optimal health benefits of reduced $\mathrm{PM}_{10}$ emissions. We note that there is a substantial mitigation potential of $\mathrm{PM}_{10}$ and $\mathrm{BC}$ emissions from open burning (Bond et al., 2004) and that the climate benefit of mitigating these emissions will be different from contained combustion as addressed in this study due to larger co-abatement of OC and other species, which has a negative RF. This implies that if in the future there will be a political objective to reduce emissions of BC from a climate perspective, current policies targeting primary $\mathrm{PM}_{10}$ from a health perspective will be inadequate.

It is important to note that when considering $\mathrm{BC}$ mitigation that the scientific uncertainties in the understanding of the climate effect of $\mathrm{BC}$ is substantial in comparison with long-lived greenhouse gases. The RF of the direct effect of BC from fossil fuels is given with an uncertainty range ( $90 \%$ ) from 0.05 to 0.35 $\mathrm{Wm}^{-2}$ and the total $\mathrm{BC}$ effect on snow and ice albedo of 0.0 to $0.2 \mathrm{Wm}^{-2}$, whereas the uncertainty in the RF from long-lived greenhouse gases is only $10 \%$ (Forster et al., 2007). Further, the semi-direct effect of BC can be significant in magnitude, but so far determination of its sign and uncertainty range remain unresolved.

A $10-30 \%$ reduction in the $\mathrm{BC}$ RF is very small compared to the expected increase in the $\mathrm{CO}_{2} \mathrm{RF}$ in most of the scenarios for future climate change. It is thus important that $\mathrm{BC}$ mitigation does not replace mitigation strategies for reduction of $\mathrm{CO}_{2}$, but 


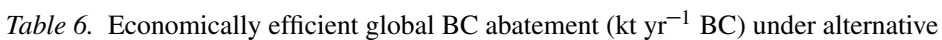
prevailing $\mathrm{CO}_{2}$ permit prices and $\mathrm{BC}$ metric in scenario $\mathrm{S} 2$. OC co-abatement is accounted for

\begin{tabular}{lcccc}
\hline Permit price in 2030 & $20 € / \mathrm{tCO}_{2}$ & $30 € / \mathrm{tCO}_{2}$ & $40 € / \mathrm{tCO}_{2}$ & $60 € / \mathrm{tCO}_{2}$ \\
\hline GWP-100 direct & 378 & 459 & 502 & 586 \\
GWP-100 total & 404 & 466 & 509 & 613 \\
GWP-100 efficacy & 423 & 485 & 522 & 632 \\
GWP-20 direct & 649 & 791 & 928 & 1008 \\
GWP-20 total & 668 & 828 & 949 & 1022 \\
GWP-20 efficacy & 707 & 898 & 966 & 1042 \\
GTP-100 total & 266 & 266 & 266 & 288 \\
GTP-20 total & 292 & 304 & 315 & 410 \\
\hline
\end{tabular}

rather complement them. An important question is yet whether the climate impact and abatement costs of $\mathrm{BC}$ indicates that it is a cost-effective means of climate mitigation, as compared to the prevailing prices of $\mathrm{CO}_{2}$ permits. This would provide justification for reducing $\mathrm{BC}$ alongside other forcing agents such as the six Kyoto Protocol gases. This depends on the value of the GWP relative to other forcing agents, which is very dependent on the time horizon considered and whether the indirect effect and enhanced efficacy is taken into account. One way to look at this is to assess how much global BC abatement is warranted under alternative prevailing $\mathrm{CO}_{2}$ permit prices. As highlighted above, our $\mathrm{BC}$ abatement costs are in annualized format, and can thus be compared to equivalent $\mathrm{CO}_{2}$ abatement costs. Table 6 explores the economically efficient $\mathrm{BC}$ abatement levels in scenario S2 for direct, total, and efficacy approaches to the 100-yr GWP of BC. Given the projected global CLE BC levels of approximately $5000 \mathrm{kt} \mathrm{BC}$ in 2030, the range of efficient $\mathrm{BC}$ abatement is between 8 and $12 \%$ for $\mathrm{CO}_{2}$ permit prices of 20-60 $€ / \mathrm{tCO}_{2}$. We see that even with a trebling of the permit price, the economical level of abatement only rises by $50 \%$.

Of course, indirect effect and especially the efficacies of BC deposited on snow provide a stronger justification for abatement. This is because the overall $\mathrm{BC}$ emission reduction is smaller to achieve 1 tonne equivalent $\mathrm{CO}_{2}$. On the other hand, the indirect component at present is more uncertain than the direct, so there can be larger obstacles to its use it in the design of BC policies. Considering a shorter time horizon than 100 years will of course also emphasize reductions in $\mathrm{BC}$ over other forcing agents. This is illustrated in Table 6 for $20 \mathrm{yr}$ time-horizon. The $20 \mathrm{yr}$ timehorizon will imply a range of efficient $\mathrm{BC}$ abatement between 13 and $20 \%$ (65-87\% higher mass of BC abated compared to using GWP-100 as a metric).

Furthermore, since the GTPs do not include the strong shortterm warming effect of $\mathrm{BC}$ immediately after the emissions, the GTPs are significantly lower than the GWPs, yielding lower levels of efficient abatement. Yet the efficient level is rather insensitive to the choice of metric (GWP-100 versus GTP-100). A decrease of the $\mathrm{BC}$ equivalent $\mathrm{CO}_{2}$ value by a factor of more than 10 only decreases the efficient global BC abatement by $30 \%$. Moreover, the ratio of efficient levels for across time horizons (20-/100-yr) is significantly different between the GWP and GTP metrics, and for GTP-100 there little sensitivity to the $\mathrm{CO}_{2}$ permit price in the range $20-40 € / \mathrm{tCO}_{2}$.

These patterns and sensitivities of efficient abatement levels can largely be explained by the shape of the MAC curve at the prevailing price of carbon. They are made up of flat sections and steep cliffs, which respectively make the efficient levels highly sensitive or insensitive to choice of metric and time horizon (see Fig. 1). The economically efficient amount of abatement depends on the point along the MAC curve upon which the $€ /$ t equivalent $\mathrm{CO}_{2}$-denominated carbon price lies. For a given carbon price, this point is different depending on the choice of metric and time-horizon. However, an initial plateau covers the abatement to approximately $225 \mathrm{ktBC}$, which is well under $€ 2 / \mathrm{tCO}_{2}$ equivalent for all the metrics and time-horizons we have examined. Thus, over the, $\mathrm{CO}_{2}$ prices we have examined, the first $225 \mathrm{ktBC}$ is always economically efficient.

Furthermore, the sensitivity of the efficient abatement level to changes in the carbon price depends on the shape of the MAC at the initial price point. For example, under the GWP metric, the MAC curve at $€ 20 / \mathrm{t}$ equivalent $\mathrm{CO}_{2}$ is generally steep, meaning a move towards $€ 60$ yields only minor additions to the efficient level. Under the GTP-100 metric, the MAC curve rises almost vertically at $€ 20 / t$ equivalent $\mathrm{CO}_{2}$, so there is very little additional economical abatement as the carbon price rises to $€ 60$. Under GTP-20, however, the curve is comparably less steep at $€ 20$, allowing for a larger increase in efficient abatement with higher prices.

Finally, we note that the overall mitigation potential estimated for 2030 derives from information about the performance of currently commercialized technical measures to improve efficiency and abate emissions. Surely, the future will bring new technologies but a more important aspect is structural changes in the energy system that would result in increased penetration of clean fuels. Consequently, adding in the analysis potential for fuel switching and impacts of future technologies would 
certainly allow for further reduction of BC RF and could lead to identifying more cost-effective solutions.

\section{Acknowledgments}

The authors would like to thank Line S. Flottorp for assistance in data management and Heidi E. Mestl and Kristin Aunan for helpful discussions. We would also like to thank Lynn Nygaard for excellent advice in preparing the manuscript. The project team is grateful for project support from the Research Council of Norway. The project has also been supported through access to the NOTUR supercomputer facilities. Zbigniew Klimont was supported by The European Network of Excellence ACCENT (Atmospheric Composition Change) of the European Commission.

\section{References}

Ackerman, A. S., Toon, O. B., Stevens, D. E., Heymsfield, A. J., Ramanathan, V. and co-author. 2000. Reduction of tropical cloudiness by soot. Science 288, 1042-1047.

Amann M., Bertok I., Cofala J., Gyarfas F., Heyes C. and co-authors. 2005. Baseline Scenarios for the Clean Air for Europe (CAFE) Programme-Final Report. IIASA, Laxenburg, Austria.

Barrie, L. A. 1986. Arctic air pollution-an overview of current knowledge. Atmos. Environ. 20, 643-663.

Berglen, T. F., Berntsen, T. K., Isaksen, I. S. A. and Sundet, J. K. 2004. A global model of the coupled sulfur/oxidant chemistry in the troposphere: the sulfur cycle. J. Geophys. Res., 109, D19310, doi:10.1029/2003JD003948.

Berntsen T. and J. S. Fuglestvedt. 2008. Global temperature responses to current emissions from the transport sectors. Proc. Natl. Acad. Sci. 105, 19154-19159

Berntsen, T. K., Fuglestvedt, J. S., Joshi, M., Shine, K. P., Stuber, N. and co-authors. 2005. Climate response to regional emissions of ozone precursors; sensitivities and warming potentials. Tellus 57B, 283-304.

Berntsen, T., Fuglestvedt, J., Myhre, G., Stordal, F. and Berglen, T. F. 2006. Abatement of greenhouse gases: does location matter? Clim. Change 74, 377-411.

Bond, T. C. and Sun, H. 2005. Can reducing black carbon emissions counteract global warming? Environ. Sci. Technol. 39, 5921-5926.

Bond, T. C., Streets, D. G., Yarber, K. F., Nelson, S. M., Woo, J.-H. and co-author. 2004. A technology-based global inventory of black and organic carbon emissions from combustion. J. Geophys. Res. 109, D14203, doi:10.1029/2003JD003697.

Bond, T. C., Habib, G. and Bergstrom, R. W. 2006. Limitations in the enhancement of visible light absorption due to mixing state. $J$. Geophys. Res. 111, D20211, doi:10.1029/2006JD007315.

Boucher, O. and Reddy, M. S. 2008. Climate trade-off between black carbon and carbon dioxide emissions. Energy Policy. 36, 193200.

Cofala, J., Amann, M., Klimont, Z., Kupiainen, K. and HöglundIsaksson, L. 2007. Scenarios of global anthropogenic emissions of air pollutants and methane until 2030. Atmos. Environ. 41, 8486-8499.

Cook, J. and Highwood E. J. 2004. Climate response to tropospheric absorbing aerosols in an intermediate general-circulation model. Q. J. R. Meteorol. Soc. 130, 175-191.
Dinwiddy, C. L. and Teal, F. J. 1996. Principles of Cost-Benefit Analysis for Developing Countries, Chapter 4. Cambridge University Press, Cambridge. ISBN 0521473586.

EIA. 2007. Annual Energy Outlook 2007. US Department of Energy, Washington. Available online: http://www.eia.doe.gov/emeu/ international/contents.html Accessed: 3 August 2007.

Flanner M. G., Zender, C. S., Randerson, J. T. and Rasch, P. J. 2007. Present-day climate forcing and response from black carbon in snow. J. Geophys. Res. 112, D11202, doi:10.1029/2006JD008003.

Forster, P., Ramaswamy, V., Artaxo, P., Berntsen, T., Betts, R. and coauthors. 2007. Changes in atmospheric constituents and in radiative forcing. In: Climate Change 2007: The Physical Science Basis. Contribution of Working Group I to the Fourth Assessment Report of the Intergovernmental Panel on Climate Change) (eds S. Solomon, D Qin, M Manning, Z Chen, M Marquis, and co-editors). Cambridge University Press, Cambridge, United Kingdom and New York, NY, USA.

Fuller, K. A., Malm, W. C. and Kreidenweis, S. M. 1999. Effects of mixing on extinction by carbonaceous particles. J. Geophys. Res., 104, 15941-15954.

Hansen, J. and Nazarenko, L. 2004. Soot climate forcing via snow and ice albedos. Proc. Natl. Acad. Sci. 101, 423-428.

Hansen, J., Sato, M. and Ruedy, R. 1997. Radiative forcing and climate response. J. Geophys. Res. 102, 6831-6864.

Hansen, J., Sato, M., Ruedy, R., Nazarenko, L., Lacis, A. and co-authors. 2005. Efficacy of climate forcings. J. Geophys. Res., 110, D18104, doi:10.1029/2005JD005776.

Haywood, J. M. and Shine, K. P. 1995. The effect of anthropogenic sulpahte and soot aerosol on the clear sky planetary radiation budget. Geophys. Res. Lett. 22, 603-606.

HTAP. 2007. Task Force on Hemispheric Transport of Air Pollution, 2007 Interim Report. http://www.htap.org/activities/2007_ Interim_Report.htm 15 .

Iversen, T. 1984. On the atmospheric transport of pollution to the Arctic. Geophys. Res. Lett. 11, 457-460.

Klimont, Z., Cofala, J., Bertok, I., Amann, M., Heyes, C. and co-author. 2002. Modelling particulate emissions in europe: a framework to estimate reduction potential and control costs. IIASA Interim Report IR-02-076.

Koch, D., Bond, T. C., Streets, D., Unger, N. and Van Der Werf, G. R. 2007. Global impacts of aerosols from particular source regions and sectors. J. Geophys. Res., 112, D02205, doi:10.1029/2005JD007024.

Koren, I., Kaufman, Y. J., Remer, L. A. and Martins, J. V. 2004. Measurement of the effect of Amazon Smoke on inhibition of cloud formation. Science 303, 1342-1345.

Kupiainen, K. and Klimont, Z. 2004. Primary emissions of submicron and carbonaceous particles in Europe and the potential for their control. IR-04-079, IIASA, Austria. http://www.iiasa.ac.at/rains/ reports.html.

Kupiainen, K. and Klimont, Z. 2007. Primary emissions of fine carbonaceous particles in Europe. Atmos. Environ. 41, 2156-2170, doi:10.1016/j.atmosenv.2006.10.066.

Myhre, G., Bellouin, N., Berglen, T. F., Berntsen, T. K., Boucher, O. and co-authors. 2007. Comparison of the radiative properties and direct radiative effect of aerosols from a global aerosol model and remote sensing data over ocean. Tellus 59B, 115-129.

Myhre, G., Berglen, T. F., Johnsrud, M., Hoyle, C. R., Berntsen, T. K. and co-authors. 2009. Modelled radiative forcing of the direct 
aerosol effect with multi-observation evaluation. Atmos. Chem. Phys., 9, 1365-1392.

Naik, V., Mauzerall, D. L., Horrowitz, L.W, Schwarzkopf, M. D., Ramaswamy, V. and co-author. 2007. On the sensitivity of radiative forcing from biomass burning aerosols and ozone to emission location. Geophys. Res. Lett. 34, L03818, doi:10.1029/2006GL028149.

O'Neill, B. C. 2000. The Jury is still out on global warming potentials. Clim. Change 44, 427-443.

Ramanathan, V. and Carmichael, G. 2008. Global and regional climate changes due to black carbon. Nat. Geosci. 1, 221-227.

Ramaswamy, V., Boucher, O., Haigh, J., Hauglustaine, D., Haywood, J. and co-authors 2001. Radiative forcing of climate change. In: Climate Change 2001: The Scientific Basis. Contribution of Working Group I to the Third Assessment Report of the Intergovernmental Panel on Climate Change (eds. JT Houghton et al.). Cambridge University Press, Cambridge, United Kingdom and New York, NY, USA, 349416.

Reddy, M. S. and Boucher, O. 2007. Climate impact of black carbon emitted from energy consumption in the world's regions. Geophys. Res. Lett. 34, L11802, doi:10.1029/2006GL028904.

Shine, K. P., Fuglestvedt, J. S., Hailemariam, K. and Stuber, N. 2005. Alternatives to the global warming potential for comparing climate impacts of emissions of greenhouse gases. Clim. Change 68, 281302 .

Schulz M., Textor, C., Kinne, S., Balkanski, Y., Bauer, S. and co-authors. 2006. Radiative forcing by aerosols as derived from the AeroCom present-day and pre-industrial simulations. Atmos. Chem. Phys. 6, 5225-5246.

Stamnes, K., Tsay, S. C., Wiscombe, W. and Jayaweera, K. 1988. Numerically stable algorithm for discrete-ordinate-method radiative-transfer in multiple-scattering and emitting layered media. Appl. Opt. 27, 2502-2509.

Stohl, A. 2006. Characteristics of atmospheric transport into the Arctic troposphere. J. Geophys. Res. 111, D11306, doi:10.1029/2005JD006888.

Streets, D. G., Bond, T. C., Lee. T. and Jang, C. 2004. On the future of carbonaceous aerosol emissions. J. Geophys. Res., 109, D24212, doi:10.1029/2004JD004902.

Warren, S. G. 1984. Impurities in snow: effects on albedo and snowmelt. Ann. Glaciol. 5, 177-179.

WHO. 2004. Health Aspects of Air Pollution. Results from the WHO project "Systematic Review of Health Aspects of Air Pollution in Europe". World Health Organization. http://ec.europa.eu/ environment/air/cafe/activities/pdf/e83080.pdf. 